\title{
Transformative Learning
}

\author{
Ed Cunliff and Jeff King
}

Transformative learning, like the Coalition of Urban and Metropolitan Universities (CUMU), has experienced substantial growth during the past few decades. The original research conducted by Mezirow (1975), who is considered the originator of the transformative learning theory, was focused on individual change: women who had been out of the workforce and were reentering. The experience was challenging in many ways, as issues of self-concept, existing frames of reference, and assumptions were beginning to change. Mezirow described the process as a structural reorganization: something that necessitates reconceiving concepts of self and one's relationships (Mezirow, 1978).

Students in higher education are voluntarily placing themselves in an environment they hope is safe and that provides them with paths to a better life. At its simplest level, for the traditional student, the transformation would be from adolescence to adulthood. If that is not a "disruptive dilemma" as Mezirow terms it, then what is? Older, non-traditional students, though, are often seeking a career change of some sort, such as the women reentering the workforce who Mezirow focused on for his initial research.

Mezirow's work is often viewed as being psychological in orientation and hence not seen as addressing social change, but this can become a "chicken or the egg" discussion. Which comes first, personal change or social change? What the authors in this volume do is present strategies in which both the community and the individuals involved have equal opportunity for transformation.

George Kuh (2008) came to the idea of High Impact Practices from the perspective of student engagement. Recognizing that not all student learning occurs in the confines of the classroom or lab, Kuh identified ten particular engagement activities that helped students' learning (some now number these at 11, with the addition of e-portfolios to the list; Watson et al., 2016). Amongst these activities are service learning/community-based learning, internships, and capstone projects. All of these approaches to student development, learning, and success can and do connect strongly with the city and regional areas served by metropolitan universities. Kuh's concepts fit well with the concept of transformative learning. They suggest that student learning benefits by participation in activities that take students out of the classroom and into the community in some fashion.

The early work of Mezirow is now viewed more broadly and links with the activities that carry students to learn outside of the classroom. For this issue of Metropolitan Universities, we focus on how institutions are helping large numbers of students to transform from adolescents to professionals in a field, or to re-design their lives through formal education.

As guest editors, we (Ed Cunliff and Jeff King) are gratified to be contributing an article about how our institution, the University of Central Oklahoma, came to Transformative Learning (TL) as a focus in helping students learn. As Oklahoma's only metropolitan-serving institution within 
the Regional University System of Oklahoma, understanding the history of a successful and ongoing TL initiative that has been operationalized in an evidence-based process can be important when seeking natural alignments between a teaching/learning approach to which a university commits and the potential for such an approach to serve metro partners and the community to the best degree possible. We offer this in hopes it can provide some guideposts for other institutions who decide to travel the TL path.

Every metropolitan area needs "professional managers with strong sustainability principles and standards,” as say Brunnquell and Brunstein in their article. Metropolitan realities in the 21st century are such that a sustainability ethos is requisite for the continuation of the city and region. Quality of life can be threatened in the absence of widespread managerial expertise in, and commitment to, sustainability. Ensuring such ethos and skill in this segment of the workforce naturally falls to metro-serving institutions, from which these managers and managers-to-be will graduate. The authors pose an intriguing idea about Transformative Learning-focused sustainability education within schools of business that moves from problem-solving to problemposing as part of a critically reflective process that will help ensure that metro-serving institutions produce sustainability-minded future managers.

Reitenauer, Draper-Beard, and Schultz write about "the transformative power of encounter" in their description of Portland State University's Inside-Out Prison Exchange Program situated within the PSU University Studies program. Sharing personal stories of transformation from an "inside student" (incarcerated), an "outside student" (PSU junior), and the PSU faculty member teaching the course, this article describes the history, institutional decisions, and activity that led to launching and maintaining Inside-Out participation, and-in the words of those changed by the experience - the program's transformative impact.

The role of the teaching and learning center at metropolitan universities is central to the development of a Transformative Learning focus in the curriculum and co-curriculum. Partnering with agencies in the metropolitan area, in service to that end, is a win-win for the university and the metropolitan community. Ableser and Moore describe how Oakland University increased community engagement via its Experiential Learning initiative as well as helped faculty and staff become more practiced in TL strategies by implementing a Universal Design for Learning (UDL) approach. Full of recommendations and tips, this article is both descriptive and prescriptive for success with TL at metro-serving institutions.

Metropolitan State University Denver was the host of the 2017 CUMU Annual Conference, and Golich, Haynes and Kreidler, from MSU Denver, provide an excellent example of how an institution can forge connections to benefit stakeholders. They describe how they have worked with employers to develop opportunities for students and to connect with economic drivers in Colorado. The approach they have utilized is to look first to the employers and discover their needs and then to match the academic and student work to help fill that gap. This shift is an important change in perspective for working with our metropolitan communities.

Layne, Kidwell and Carney describe a capstone course that helps students transform through a program that connects them with real world problem solving in the agricultural and food service industries. The connection they describe helps students obtain some of the skills that might be 
difficult or impossible to get solely in the classroom setting. This is an opportunity for students to better transfer learnings to work environments, and also helps faculty and industry create stronger communication systems and bonds.

Sims and Scott offer insight into diversity programs from two different universities. They address issues in diversity that are part of metropolitan areas in highly replicable fashion. The transformative nature of the programs are well-founded in Transformative Learning theory, and are described with clarity, thus facilitating replication. Both programs are strongly driven by faculty initiative and are managed in self-sustaining models that allow direct benefits to students and to the institutions.

We are grateful to Metropolitan Universities editor Valerie Holton, $\mathrm{PhD}$, for offering us the opportunity to co-edit an issue on transformative learning in Metropolitan Universities. Having started our separate careers during an era when "town and gown" was the phrase used to describe the relationship between higher education institutions and their home communities, it is exciting to now be in an era where collaboration and mutual benefit are the focus. 


\section{References}

Kuh, G. D. (2008, September 30). High-impact educational practices: What they are, who has access to them, and why they matter. Washington, DC: Association of American Colleges \& Universities.

Mezirow, J. (1975). Education for perspective transformation: Women's reentry program in community colleges. New York, NY: Center for Adult Education, Teachers College, Columbia University.

Mezirow, J. (1978). Perspective Transformation. Adult Education, 28(2), 100-110.

https://doi.org/10.1177/074171367802800202

Watson, C. E., Kuh, G. D., Rhodes, T., Light, T. P., \& Chen, H. L. (2016). Editorial: ePortfolios

— the eleventh high impact practice. International Journal of ePortfolio, 6 (2), 65-69. Retrieved from http://www.theijep.com/pdf/IJEP254.pdf 


\section{Author Information}

Ed Cunliff is professor of Adult and Higher Education at the University of Central Oklahoma with a consulting practice in transformative learning and authentic leadership. Ed's seeks to help learners achieve their goals, which he accomplishes through teaching/facilitating learning in the Adult and Higher Education program at the University of Central Oklahoma. Teaching and research interests include adult learners, applied research, transformative learning, managing adult education programs, and the organization and administration of higher education.

\section{Ed Cunliff}

Department of Adult Education and Safety Sciences

University of Central Oklahoma

100 N. University Drive

Box 206, CTL 221

Edmond, OK 73034

Email: ecunliff@uco.edu

Telephone: 405-974-2972

Jeff King is Executive Director of the Center for Excellence in Transformative Teaching and Learning at the University of Central Oklahoma. He also leads the Student Transformative Learning Record (STLR) initiative, which is comprised of the processes, tools, and infrastructure UCO employs to operationalize Transformative Learning. As part of his STLR duties, Jeff works with other institutions who have adopted or adapted STLR to their own campuses, missions, and cultures.

Jeff King

Center for Excellence in Transformative Teaching and Learning University of Central Oklahoma

100 N. University Drive

Box 212, CTL 205

Edmond, OK 73034

Email: jking47@uco.edu

Telephone: 405-974-5544 